\title{
Roteiro geoturístico de Chapada dos Guimarães: uma proposta de educação em geociências
}

\author{
Geotouristic guide of Chapada dos Guimarães: a proposal ofeducation in \\ geociences
}

\author{
Caiubi Emanuel Souza Kuhn ${ }^{\mathrm{a}}$ \\ Thaís Cardoso Tobias ${ }^{\mathrm{b}}$
}

\begin{abstract}
${ }^{a}$ Mestre em Geociência pela UFMT, coordenador da Câmara Setorial Temática do Geoparque de Chapada dos Guimarães da Assembléia Legislativa do Estado de Mato Grosso, professor do Instituto de Engenharia da Universidade Federal de Mato Grosso: caiubigeologia@hotmail.com

${ }^{\mathrm{b}}$ Mestra em Geologia pela Universidade de Brasília, membra da Câmara Setorial Temática do Geoparque de Chapada dos Guimarães da Assembleia Legislativa do Estado de Mato Grosso. Endereço eletrônico: thaispaleonto@gmail.com
\end{abstract}

Recebido em: 24/03/2017 I Aceito em: 02/06/2017

ARTIGO

\begin{abstract}
RESUMO
Uma das necessidades da sociedade é compreender as limitações de nosso planeta, pois apenas entendendo os mecanismos que o regem será possível tomar decisões mais conscientes para a sua preservação. A geociência se ocupa de estudar a formação, composição, os processos e a história do planeta Terra.Sendo assim, através do estudo deste campo da ciência é possível compreender processos que ocorrem no planeta em uma diferente escala de tempo, ou seja, que estão fora do tempo de observação da vida humana como, por exemplo, a formação e fragmentação de supercontinentes como o Pangea. Devido à história geológica, algumas regiões possuem vocação para desenvolvimento de roteiros geoturísticos, onde além da beleza cênica, há o registro físico, que permitem ao visitante poderaprender também sobre os processos que deram origem as rochas, ao relevo, os solos, e diversos outros elementos da natureza abiótica que, por conseguinte, interferem direta ou indiretamente na natureza biótica. Depois de apresentar a importância da divulgação do conhecimento da geociência, este trabalho apresenta uma proposta de roteiro geoturístico, no município de Chapada dos Guimarães ,no qual é possível observar rochas de diferentes composições e ambientes deposicionais, compreender processos geomorfológicos e intempéricos, além de poder desfrutar de um roteiro com cachoeiras e belas paisagens, utilizando assim atrativos turísticos como instrumento de ensino.
\end{abstract}

Palavras-chave: Geoturismo. Desenvolvimento. Aula de campo. Educação em geociências. 


\begin{abstract}
One of the needs of society is to understand the limitations of our planet, because only by understanding the mechanisms that govern it will it be possible to make more conscious decisions for its preservation. Geoscience is concerned with studying the formation, composition, processes and history of planet Earth. Thus, through the study of this field of science it is possible to understand processes that occur on the planet on a different time scale, that is, they are outside the time of observation of human life, such as the formation and fragmentation of supercontinents as The Pangea. Due to the geological history, some regions have a vocation for the development of geotourism scripts, in addition to the scenic beauty, there is the physical registry, which allows the visitor to also learn about the processes that gave rise to rocks, relief, soils, and various Other elements of the abiotic nature that, therefore, interfere directly or indirectly in the biotic nature. After presenting the importance of the dissemination of geoscience knowledge, this work presents a proposal of geotourism script, in the Municipality of Chapada dos Guimarães, in which it is possible to observe rocks of different compositions and depositional environments, to understand geomorphological and intemperic processes, besides power Enjoy a route with waterfalls and beautiful landscapes, thus using tourist attractions as a teaching tool.
\end{abstract}

Keywords: Geotourism. Field Trips. Education.Geosciences

\title{
1 INTRODUÇÃO
}

A União das Nações Unidas (ONU) declarou o ano de 2017 como o ano Internacional do Turismo Sustentável para o Desenvolvimento. Dentre as diversas formas de turismo, o Geoturismo se destaca como uma vertente do turismo de natureza que ganha cada vez mais força, principalmente devido aos avanços ocasionados pela criação de geoparques. O Geoturismo é realizado em locais onde se tenha uma geodiversidade representativa. Para Pereira et al., (2008, p. 2)

\footnotetext{
[...] a geodiversidade engloba não só minerais e rochas, mas também fósseis, solos, formas de relevo e processos geológicos ativos que lhes dão origem. Sendo assim, a geodiversidade pode ser considerada como a principal causa para a variedade de ambientes onde a vida surgiu e evolui. Neste sentido, o estudo da geologia associado a outras áreas do conhecimento, tais como química, física e biologia, permite compreender a história do nosso planeta e da evolução dos seres vivos.
}

Desta forma, a compreensão dos conceitos das Geociências é fundamental para que o ser humano possa entender o meio onde vive e suas limitações e assim fazer melhor uso do meio ambiente, garantido sua preservação para gerações futuras. Para Pereira et al., (2008), esse conhecimento é adquirido através do estudo das rochas, dos fósseis, das estruturas geológicas e das formas do relevo.

Em Chapada dos Guimarães, localizada a cerca de 60 km de Cuiabá, capital do Estado de Mato Grosso, é possível observar uma estratigrafia que aborda desde 
o Neoproterozoico, Paleozoico, Mesozoico e Cenozoico. A proximidade da capital e a representativa geodiversidadetorna Chapada dos Guimarães uma excelente sala de aula e forte candidata a se tornar um geoparque, o que inclusive já foi proposto pelo Serviço Geológico do Brasil -CPRM (VIEIRA JÚNIOR et al., 2011).

Além da estratigrafia, Chapada dos Guimarães apresenta belezas cênicas resultantes do relevo escarpado da borda do Planalto em rochasareníticas das formações Furnas e Botucatu (SCHREINER, 2009). As bordas da subunidade Chapadados Guimarães contornam a superfície pediplanada daDepressão Cuiabana por meio de escarpas e ressaltossustentados por arenitos da Formação Furnas e argilitosda Formação Ponta Grossa, bordejado por morros comcristas ravinadas, exumados pelo recuo da escarpa,marcando a transição entre a Depressão e o Planalto(PRADO et al., 2014).

São descritos diversos tipos de solos tais como: Latossolos, Neossolos Regolíticos, Neossolos Litólicos, Neossolos Quartzarênicos, Argissolos, Plintossolos, Gleissolos e Organossolos (VIEIRA JÚNIOR et al., 2011; CAMARGO, 2011; VASCONCELOS, 2007 apud PRADO et al., 2014).

O conjunto destes elementos geológicos, geomorfológicos e pedológicos, permite o desenvolvimento de um roteiro didático aplicado a geociências, desenvolvido em um cenário com paisagens e cachoeiras belíssimas. Sendo assim, este artigo apresenta a proposta de um roteiro de aula de campoadaptável para alunos de diferentes níveis educacionais, a ser realizado em Chapada dos Guimarães.

\section{METOLOGOGIA}

Antes da execução da aula de campo é necessário desenvolver uma revisão bibliográfica da geologia regional de Chapada dos Guimarães, aplicando uma terminologia em uma linguagem didática de mais fácil compreensão (ver Geologia Regional). A proposta de roteiro apresentada pode ser realizada entre dois a quatro dias de aulas, com pernoite em Chapada dos Guimarães. Para fins didáticos, foi desenvolvido material complementar tais como desenhos esquemáticos, assim como a apresentação dos principais tópicos a serem abordados em cada ponto visitado. $\mathrm{O}$ conteúdo apresentado neste artigo foi resultado de um roteiro desenvolvido para as atividades de campo das disciplinas de Geologia Geral do Curso de Engenharia de 
Minas e Geologia para Engenharia de Transportes da Universidade Federal de Mato Grosso.

\section{GEOLOGIA REGIONAL}

Em Chapada dos Guimarães afloram rochas ígneas, metamórficas e sedimentares de diferentes idades,desde oEonNeoproterozóico até o Período Terciário, formadas em diferentes ambientes, através de diferentes processos, desde sedimentos que se depositaram em um ambiente marinho raso, assim como o registro de um antigo deserto, eos depósitos fluviais continentais nos quais durante décadas foram extraídos diamantes. Para compreender essa história é preciso um rápido estudo sobre a geologia local, desde a evolução da Faixa Paraguai e as rochas do Grupo Cuiabá; até a deposição das rochas da Bacia do Paraná, composta na região pelo Grupo Rio Ivaí, e pelas formações Furnas, Ponta Grossa e Botucatu; a Bacia do Cambambe e as Formações Paredão Grande, Quilombinho, Cachoeira do Bom Jardim e Cambambe, e por fim, a Formação Cachoeirinha.

A Faixa Paraguai constitui um cinturão de montanhas dobradas que abrangem aproximadamente $1.200 \mathrm{~km}$ de comprimento, interpretada como relacionadas a um ciclo de abertura e fechamento de um oceano(MANZANO et al., 2008).O domínio oceânico teve início entre 900 e 800 Ma e seu fechamento ocorreu entre 890 a $630 \mathrm{Ma}$, resultando na formação de uma imensa cadeia de montanha similar ao Himalaia(DANTAS et al., 2007 apud De Min et al., 2013). Esse processo também formou o supercontinenteGondwana, resultado dasuturado crátonOcidental Africano contra o SaharaMetacraton no norte, eo cráton Amazônico contra o cráton do São Francisco no sul (CHIARAMONTI et al., 2014).

O Grupo Cuiabá é constituído pelos sedimentos que sofreram metamorfismo regional durante a formação da Faixa Paraguai. Sua litologia é caracterizada por metaconglomerados, quartzitos; filitos,filitosardosianos,metagrauvacas,metarcóseos, metarritmitos e metarenitos (GUIMARÃES \& ALMEIDA, 1972 apud TOKASHIKI \& SAES, 2008; MANZANO et al., 2008).

Ainda neste imenso cinturão de montanhas representado pela Faixa Paraguai, ocorreu a intrusão de diversos corpos ígneos graníticos (rocha ígnea intrusiva). Datado por Amaral et al. (1966) em $504 \pm 12$ Ma, por Hasui\& Almeida (1970) em503 Ma e por Almeida \& Mantovani(1975) em $500 \pm 15$ Ma. O Granito de 
São Vicente é composto por biotita sieno a monzogranitos e muscovita-biotita sienogranitos (MANZANO et al., 2008, p. 501), está localizado próximo ao Município de Chapada dos Guimarães. No entorno deste corpo ígneo é possível observar o metamorfismode contato nas fácies albita e hornblendahornfels (MANZANO et al., 2008)

A Bacia do Paraná abrange uma área de $1.700 .000 \mathrm{~km}^{2}$, no qual a sedimentação foi resultado de eventos eustáticos e tectônicos de segunda ordem (ou seja, variação do nível do mar, com entrada do mar sobre o continente transgressão marinha - e o recuo do mar - regressão marinha) que deram origem a seis supersequênciasdeposicionais: 1) Rio Ivaí (Ordoviciano - Siluriano),2) Paraná (Devoniano), 3) Gondwana I (CarboníferoeTriássico Inicial), 4) Gondwana II (Triássico Tardio), 5) Gondwanalll (Jurássico e Cretáceo Inferior), 6) Bauru (Cretáceo Superior) (MILANI, 1997 apud PIRES et al., 2011).

Conforme Vieira Júnior et al., (2011), aSupersequência Rio Ivaí é um ciclo transgressivo, relacionado à fase riftda bacia, representado pelo grupo de mesmo nome e compreende arenitos depositados em ambiente fluvial, transicional e costeiro, diamictitos de origem glacial e folhelhos, hospedando a superfície de inundação máxima.

"A Superseqüência Paraná iniciou com os depósitosareno-conglomeráticos da Formação Furnas,Eodevoniano (410 Ma), recobertos por pelitosfossilíferosda Formação Ponta Grossa (Emsiano-400 Ma/Frasniano-375 Ma)" (BOCARDI et al., 2008, p. 210).

A Formação Furnas constitui-se de arenitos médios a grossos, em geral, esbranquiçados, caulínicos, moderadamente selecionados angulosos a subangulosos, ocorre a presença de níveis de seixos imbricados em granodecrescência ascendente, a estratificação ocorre como plano-paralela, cruzadas planares e cruzadas acanaladas sendo esta última a mais notável (SCHNEIDER et al., 1974, MACHADO et al., 2009). Esta sedimentação continental e litorânea, respectivamente, passa gradativamente para uma sedimentação marinha (ASSINE et al., 1998, MILANI, 1997)

A Formação Ponta Grossa constitui-se por folhelhos e folhelhos sílticos e siltitos cinza escuros a pretos, localmente carbonosos, fossíliferos ou micáceos, e arenitos finos a muito finos, micáceos, intercalados àquelas camadas de sedimentos 
mais finos (SCHNEIDER et al., 1974). Esta unidade litoestratigráfica destaca-se por possuir fósseis de Brachiopoda (Lingulida, Stropomenida, Speriferida, Terebratulida) conforme Quadros $(1979,1987)$ e trilobitas (CARVALHO \& PONCIANO, 2015).

A Formação Botucatu possui idade jurássica (PIRES et al., 2011) e foi depositada em um ambiente desértico, no interior do continenteGondwana. Conforme Schneider et al. (1970) apud Silva (2014) e Machado et al. (2009), esta unidade é constituída por arenitos avermelhados, róseos ou arroxeados, de granulometria fina a média,passando para grossos na base, bem selecionado, friáveis, textura bimodal, grãos esféricos, arredondados e foscos. Em Chapada dos Guimarães, as estratificações cruzadas tangenciaisde grande porte, plano-paralelas e cruzada acanalada são observadas.

A Bacia do Cambambe foi proposta por Coimbra (1991) e está relacionada aos esforços de fragmentação do continenteGondwana. Nesta época (aproximadamente 84 milhões de anos), a África e a América do Sul começavam a se afastar, ou seja, o oceano Atlântico estava se expandindo através da formação de placa oceânica na dorsal meso-oceânica (região entre bordas divergentes de placas tectônicas onde o magma do manto ascende, através de correntes de convecção, resultando no movimento de afastamento das placas tectônicas e formação de assoalho oceânico). Apesar de distante do litoral, estes esforços tectônicos afetaram também a região de Chapada dos Guimarães e propiciaram a deposição das rochas da Bacia Cambambe. Estas rochas guardam dentro delas importantes conteúdos fossilíferos de dinossauros conforme descrito por Derby (1890), Franco-Rosa et al., (2004) e Souza et al (2011).

Já a Formação Paredão Grande foi proposta por Weskaet al., (1996) para agrupar rochas piroclásticas grossas e finas, derrames e diques associados que ocorrem nos munícipios de Chapada dos Guimarães, Dom Aquino, Paranatinga, Poxoréu, distrito de Paredão Grande e Colônia Indígena Meruri. Conforme Gibson et

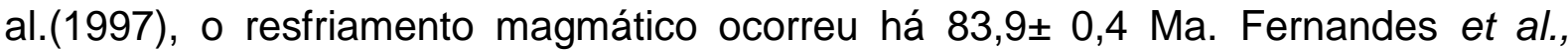
(2016) descreve basaltos que afloram na Passagem do Mamão (hoje Balsa do João Carro - MT 020), em Chapada dos Guimarães na forma de paredões de pequeno porte com moderado grau de intemperismo.

As formaçõesQuilombinho e Cachoeira do Bom Jardim compõem o Grupo Ribeirão Boiadeiro, e foram depositadas em um ambiente de leques aluviais. As 
relações entre a sedimentação e o vulcanismo permite dizer que a deposição destas formações ocorreu no final do Andar Santoniano (86.3 - 83.3 Ma) e início do Andar Campaniano (83.3 - $72.1 \mathrm{Ma})$.

A Formação Quilombinho representa a porção proximal deste sistema, e a sedimentação desta unidade é composta por conglomerados polimíticos com clastos abundantes de rochas vulcânicas e arenitos mal selecionados róseos a vermelhos (WESKA, 2006; KUHN, 2014).

A Formação Cachoeira do Bom Jardim corresponde à porção distal do sistema de leques aluviais. As estruturas primárias são laminações plano-paralelas e estratificações cruzadas, cruzadas acanaladas a tabulares tangenciais. Calcretes ocorrem em bancos espessos interdigitados nos arenitos, argilitos e conglomerados. As cores dos pacotes são vermelha, rosa e branca (WESKA, 1987, 2006; KUHN, 2014).

A Formação Cambambe é constituída por arenitos de cor predominante branca e vermelho, creme e cinza com raros conglomerados polimíticos, e em pacotes, o arcabouço aberto (WESKA, 2006; KUHN, 2014). Devido às relações estratigráficas com as formações anteriores e dada a ocorrência de fósseis de dinossauros, é possível estabelecer que a deposição desta formação ocorreu entre os andares Campaniano (83.3 - 72.1 Ma) e Maastrichtiano(72.1 - 66.0 Ma)(KUHN, 2014).

A Formação Cachoeirinha foi a última unidade a ser depositada na área abordada por esse artigo. Conforme Zolingeret al., (2002) a Formação Cachoeirinha possui idade terciáriae é a fonte de depósitos detríticos de cascalhos quaternários diamantíferos. Esta formação é composta por sedimentos inconsolidados a consolidados, que variam entre argilas, areias argilosas, areias cascalhosas e cascalhos, parcialmente laterizados. Estas rochas despertam interesse devido a ocorrência de depósitos de diamantes (WESKA, 1996, ZOLINGER et al., 2002). 


\section{PROPOSTA DE AULA DE CAMPO}

A aula de campo desenvolvida aborda afloramentos localizados próximos a estradas e/ou acessíveis por meio de trilhas (Tabela I).

Tabela I - Afloramentos visitados durante aula de campo realizado na disciplina de geologia para Engenharia de Transportes.

\begin{tabular}{c|c|c|c|c}
\hline PONTO & $\begin{array}{c}\text { PONTO DE } \\
\text { REFERÊNCIA }\end{array}$ & \multicolumn{2}{c|}{ COORDENADA } & $\begin{array}{c}\text { ELEVAÇÃO } \\
\text { (M) }\end{array}$ \\
\hline 1 & Rodovia MT-251 & 0624886 & 8303659 & 327 \\
\hline 2 & Trilha do Mel & 0624175 & 8299764 & 577 \\
\hline 3 & Véu das Noivas & 0625341 & 8296133 & 592 \\
\hline 4 & $\begin{array}{c}\text { Estrada de acesso - } \\
\text { Próximo a sede do } \\
\text { parque ICMBio }\end{array}$ & 0625133 & 8296171 & 618 \\
\hline 5 & $\begin{array}{c}\text { Cachoeira do Pulo - } \\
\text { Circuito das Cachoeiras }\end{array}$ & 0624316 & 829567 & 600 \\
\hline 6 & $\begin{array}{c}\text { Cachoeira do Degrau } \\
\text { Estrada da Água Fria - } \\
\text { MT 020; km 17 }\end{array}$ & 0624316 & 8295302 & 586 \\
\hline 8 & $\begin{array}{c}\text { Estrada da Água Fria - } \\
\text { MT 020; km 19 }\end{array}$ & 0690623 & 8306509 & 580 \\
\hline 9 & $\begin{array}{c}\text { Afloramento - MT 020; } \\
\text { Balsa do João Carro }\end{array}$ & 0641783 & 8328287 & 295 \\
\hline 10 & $\begin{array}{c}\text { Mirante - Chapada dos } \\
\text { Guimarães }\end{array}$ & 0640746 & 8288041 & 776 \\
\hline 11 & Cachoeira da Martinha & 0671113 & 8284881 & 617 \\
\hline
\end{tabular}

PONTO 1 - Objetivo principal é compreender as discordâncias (Figura 1, A e B), ou seja, as descontinuidades existentes,que são linhas que representam um hiato deposicional, isto é, um período de tempo no qual não se tevedeposição ou então que os processos da dinâmica externa do nosso planeta realizaram a erosão das unidades depositadas durante um determinado espaço de tempo. Neste afloramento é possível observar duas destas discordâncias,sendo a primeira delas entre o Neoproterozoico (1000 - $541 \mathrm{Ma}$; rochas do Grupo Cuiabá) e o Siluriano (443 - $419 \mathrm{Ma}$; rochas da Formação Furnas), e a segunda entre o Siluriano e Jurássico (201 - $145 \mathrm{Ma}$; rochas da Formação Botucatu). Além disso, este é um excelente ponto para se observar as diferenças geomorfológicas entre as formações geológicas, permitindo assim compreender um pouco sobre o processo de erosão. A 
existência de três tipos de rochas de diferentes idades, composição e ambientesdeposicionais, permite abordar sobre a tectônica de placas, a movimentação dos continentes ao longo do globo e as mudanças ambientais que ocorreram no ambiente ao longo do tempo geológico. Em uma mesma paisagem é possível observar: 1) rochas metamórficas resultado dos processos metamórficos que ocorrem durante a formação da Faixa Paraguai; 2) rochas sedimentares da Formação Furnas, depositadas em um ambiente de sedimentação continental e litorânea, que evolui gradativamente para marinho raso; e 3) os arenitos eólicos da Formação Botucatu.
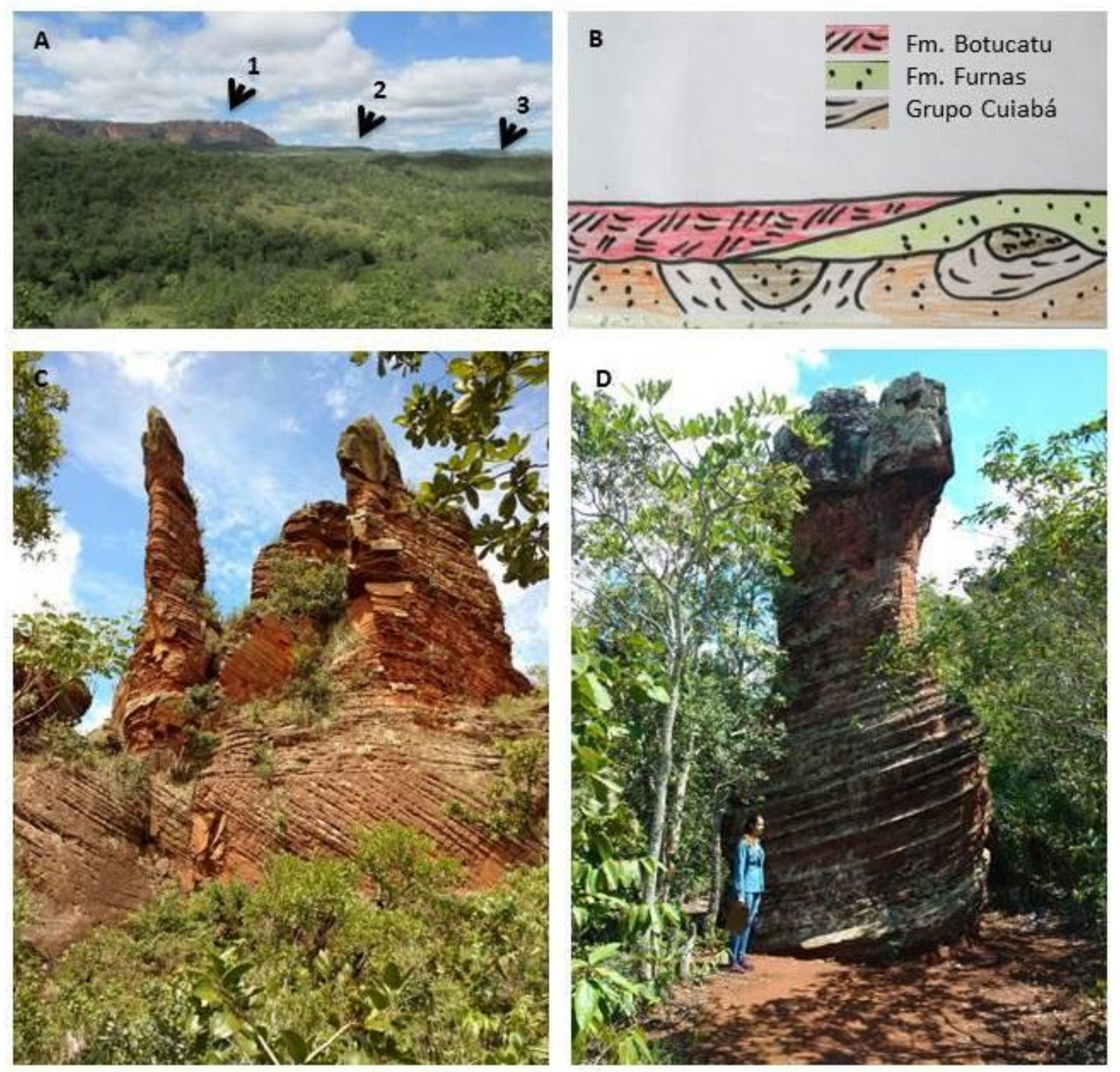

Figura 1: A) Na foto é possível observar as unidades litológicas: Grupo Cuiabá (3), Formação Furnas (2), Formação Botucatu (1). B) Figura esquemática, para auxiliar na explicação das discordâncias observadas na figura (A). C) Arenito com estratificações cruzadas acanaladas de grande porte da Formação Botucatu. D) "Pedra Parafuso" - resultado da erosão diferencial. 
PONTO 2 - A trilha do mel está localizada próxima a MT 251. Durante o percurso é possível observar as paleodunas do deserto do Botucatu (Figura 1, C e D). As estratificações cruzadas de grande porte permitem abordar temas como o transporte eólico e a variação do vento e com a isso a variação no tamanho dos grãos depositados. No local existem feições ruiniformes resultado da erosão diferencial, também é possível observar relevos residuais e diferenças geomorfológicas (Figura 2, A) entre a paisagem relacionada às rochas do Grupo Cuiabá e a paisagem resultante da evolução geomorfológica relacionada à Formação Botucatu. A formação Botucatu possui uma ótima capacidade de armazenar e transmitir água entre seus poros, tanto que nestas rochas está situado o famoso Aquífero do Guarani.
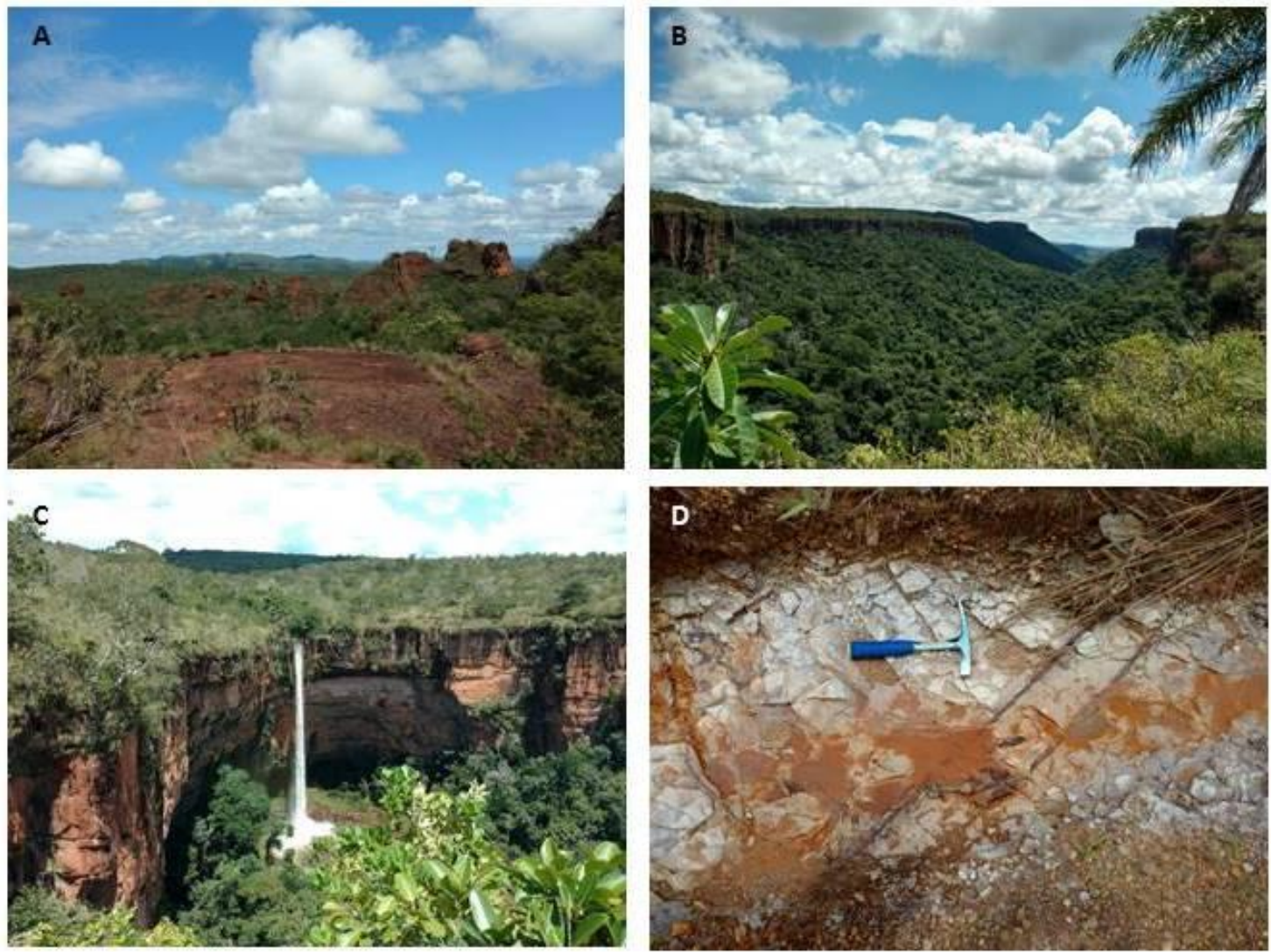

Figura 2: A) Paisagem observada na trilha do mel, ao fundo morros e morrotes onde afloram as rochas do Grupo Cuiabá, a frente relevo ruiniforme característico da Formação Botucatu. B) Canion do Veú da noiva. C) Cachoeira do Veú da Noiva; D) Folhelhos fossilíferos da Formação Ponta Grossa.

O acesso aos pontos 3 a 6 se faz por meio da MT 251. É possível seguir com veículos até o estacionamento do Parque Nacional.Contudo, os percursos devem ser desenvolvidos através de trilhas a pé. 
PONTO 3 -A Cachoeira do Véu de Noiva (Figura 2, C) possui 86 metros de queda livre. $O$ arenito da Formação Furnas constitui as escarpas que formam o canion(Figura 2, B).

PONTO 4 -Nas proximidades da sede do parque afloram os folhelhos fossilíferos (Figura 2, D) de idade devoniana da Formação Ponta Grossa. Ao caminhar pelo local é possível encontrar braquiópodes fossilizados (conchas petrificadas do filo Brachiopoda) o que permite mais uma vez abordar sobre o oceano que já recobriu a região. A ocorrência de fósseis no Parque Nacional permite abordar sobre a evolução biológica e a sucessão faunística. Desta forma, os conteúdos fossilíferos auxiliam a revelar a idade de uma rocha, visto que cada espécie possui um tempo específico em que existiu no nosso planeta.

Os pontos 5 e 6 estão localizados no Circuito das Cachoeiras do Parque Nacional, onde só é possível o acesso acompanhado de guia de turismo habilitado. Neste roteiro, além da geodiversidade, os visitantes podem observar a biodiversidade do cerrado e aproveitarem para se refrescar nas águas das cachoeiras.

PONTO 5 - Na Cachoeira do Pulo (Figura 3, B) é observada inloco a discordância (Figura 3, A) existente entre o Grupo Cuiabá (Figura 3, C) e a Formação Furnas (Figura 3, D). Na base da cachoeira observam-se metadiamictitos, com foliações metamórficas e veios de quartzo. Logo acima, encontram-se os arenitos grosseiros, com estratificação cruzada, intercalados com níveis conglomeráticos, que correspondem à sedimentação continental-litorânea. O contato entre rochas metamórficas e sedimentares é uma oportunidade para abordar sobre as características de cada um dos tipos de rochas. Além de relembrar sobre os processos erosivos que ocorrem após a formação da Faixa Paraguai.

PONTO 6 - A geomorfologia da cachoeira do Degrau (Figura 3, E) e da cachoeira da Prainha se desenvolveu devido à diferença litológica das rochas do Grupo Cuiabá existente. No local afloram filitos, metadiamictitos e quartzitos dobrados e durante o processo de intemperismo, cada um dos dois tipos de rochas reagiu de forma diferente (Figura 3, E), sendo que as rochas de quartzito, devido a maior resistência ao intemperismo, destacaram-se no relevo. 
Os pontos 7 a 9 localizam-se as margens da MT 020, e o final do roteiro está localizado as margens do lago do Manso. Neste roteiro são observadas as rochas de idades cretáceas e terciárias.
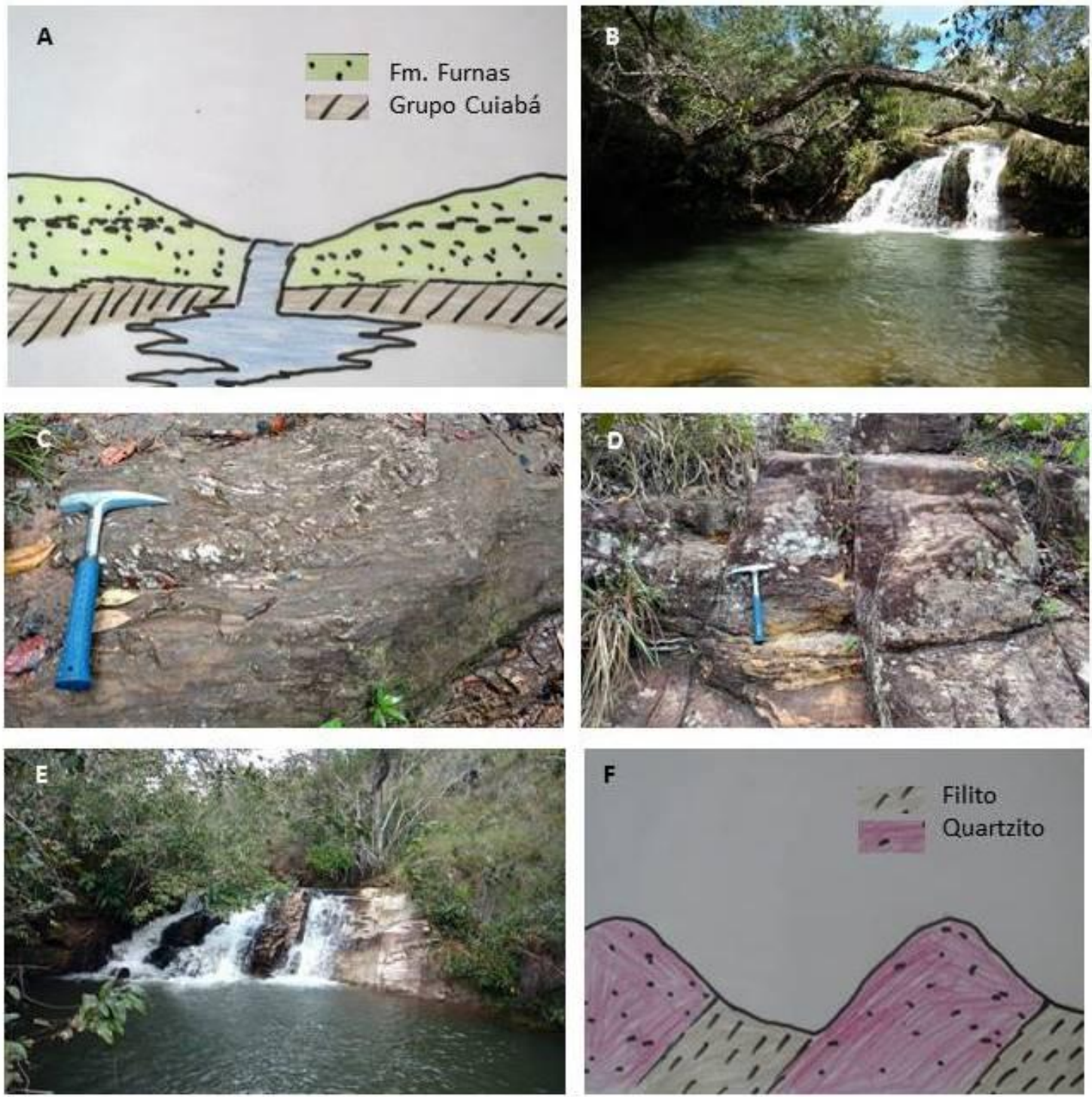

Figura 3: A) Desenho esquemático da discordância existente entre o Grupo Cuiabá e a Formação Furnas observada na Cachoeira do Pulo. B) Cachoeira do Pulo. C) Metadiamictitos do Grupo Cuiabá, aflorantes na base da Cachoeira do Pulo; D) Formação Furnas: Arenito grosso, com estratificação cruzada, intercalado com lentes e níveis de conglomerados. E) Cachoeira Degrau. F) Desenho esquemático, para explicação da erosão diferencial existente nas proximidades da Cachoeira Degrau.

PONTO 7 - Neste local afloram as rochas da Formação Quilombinho, constituída por conglomerados polimíticos(Figura 4, C)com clastos abundantes de rochas vulcânicas e arenitos mal selecionados vermelhos, depositadas em um sistema de leques aluviais. São descritos desde seixos de alguns centímetros a matacões com até $1,20 \mathrm{~m}$. O tamanho dos clastos depositados é resultado da energia de corrente. 
PONTO 8 - Neste afloramento é observada uma discordância entre as rochas da Formação Quilombinho e a Formação Cachoeirinha (Figura 4, A e B). Devido à diferença litológica entre as unidades é observado que a ação do intemperismo age de forma mais intensa nos conglomerados da Formação Quilombinho, em virtude dos seixos desta unidade serem predominantemente de rochas vulcânicas. Enquanto as rochas da Formação Cachoeirinha, mesmo estando posicionada no topo do afloramento, quase não apresentam alteraçõesintempéricas devido à mineralogia dos seixos,compostos de quartzitos e quartzo. Os conglomerados da Formação Cachoeirinha possuem uma importância econômica devido à ocorrência de diamantes nesta unidade. Cabe relembrar que os diamantes não tiveram sua origem nestas rochas, e que estes depósitos estão relacionados ao transporte fluvial. Duas comunidades em Chapada dos Guimarães possuem sua história relacionada ao garimpo de diamantes, sendo elas a Água Fria e Cachoeira Rica.
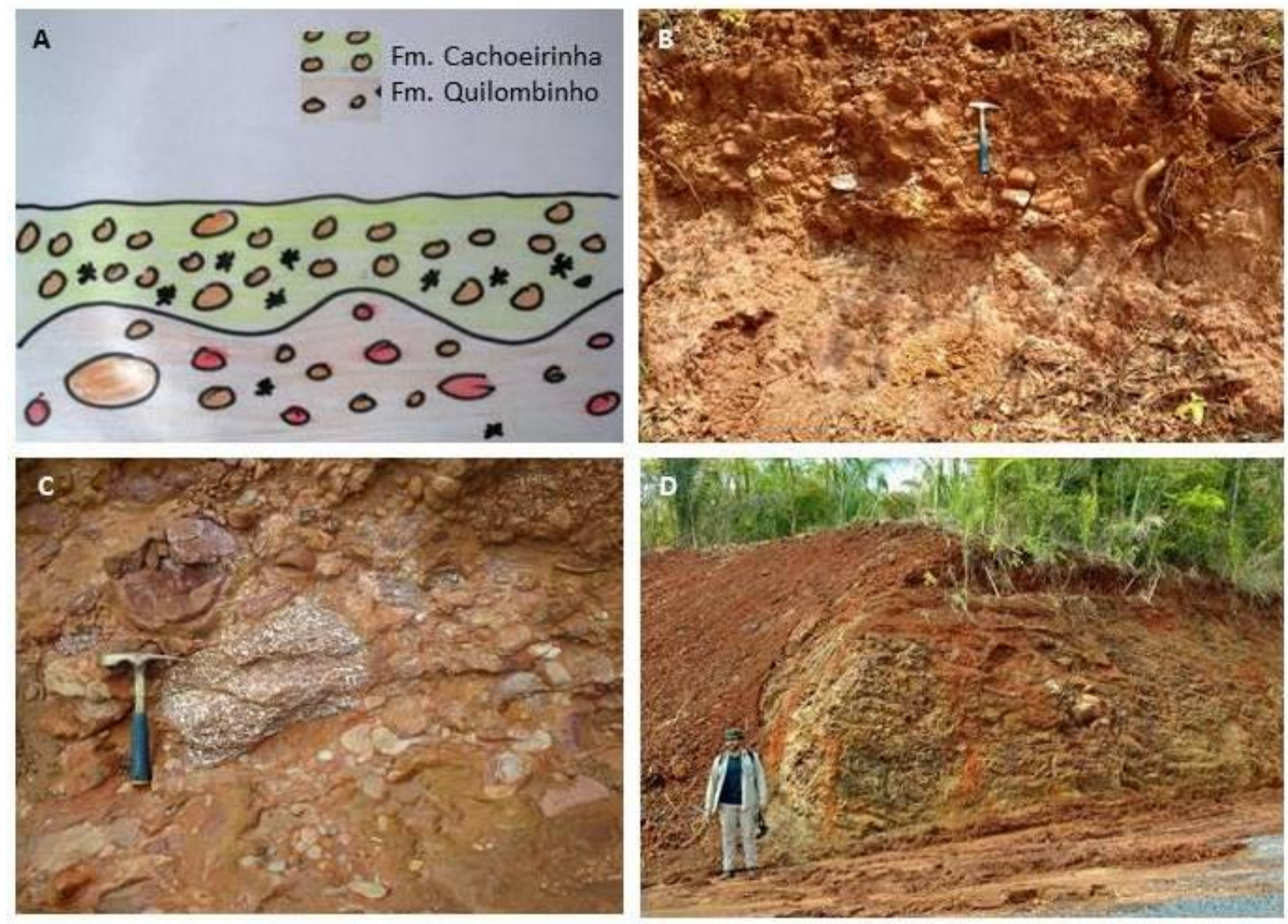

Figura 4: A) Desenho esquemático da discordância existente entre a Formação Quilombinho e a Formação Cachoeirinha. B) Foto da discordância entre as formações Quilombinho (base) e Cachoeirinha (topo), na figura é possível observar a diferença dos efeitos intempericos em ambas as unidades. C) Conglomerado polimítico da formação Quilombinho. D) Afloramento do Basalto da Formação Paredão Grande.

PONTO 9 - As margens do lago do Manso afloram as rochas basálticas da Formação Paredão Grande. O Basalto (Figura 4, D) é uma rocha ígnea extrusiva, ou 
seja, que se cristaliza na superfície ou muito próximo dela. A ocorrência de rochas de origem vulcânica chama atenção de estudantes e turistas, visto que hoje no Brasil não existam vulcões ativos. A utilização de recursos hídricos para geração de energia é outro aspecto que pode ser abordado neste local.

Próximo ao Ponto 9 está localizado o Morro do Cambambe, onde afloram as rochas da Formação Cachoeira do Bom Jardim e Formação Cambambe.Neste local já foram encontrados diversos fósseis de dinossauros.

PONTO 10 - Retornando a MT 251, o Mirante do Centro Geodésico (Figura 5, A), está localizado a sete quilômetros de Chapada dos Guimarães, no sentido Campo Verde. Neste local é possível observar a evolução geomorfológica regional, as diferentes superfícies de aplainamento e o relevo residual resultante da erosão das rochas do Grupo Cuiabá. Outro local que vale apena ser visitado é o Mirante do Alto do Céu, onde também se observa os mesmos aspectos do Mirante do Centro Geodésico, mas a paisagem é única.
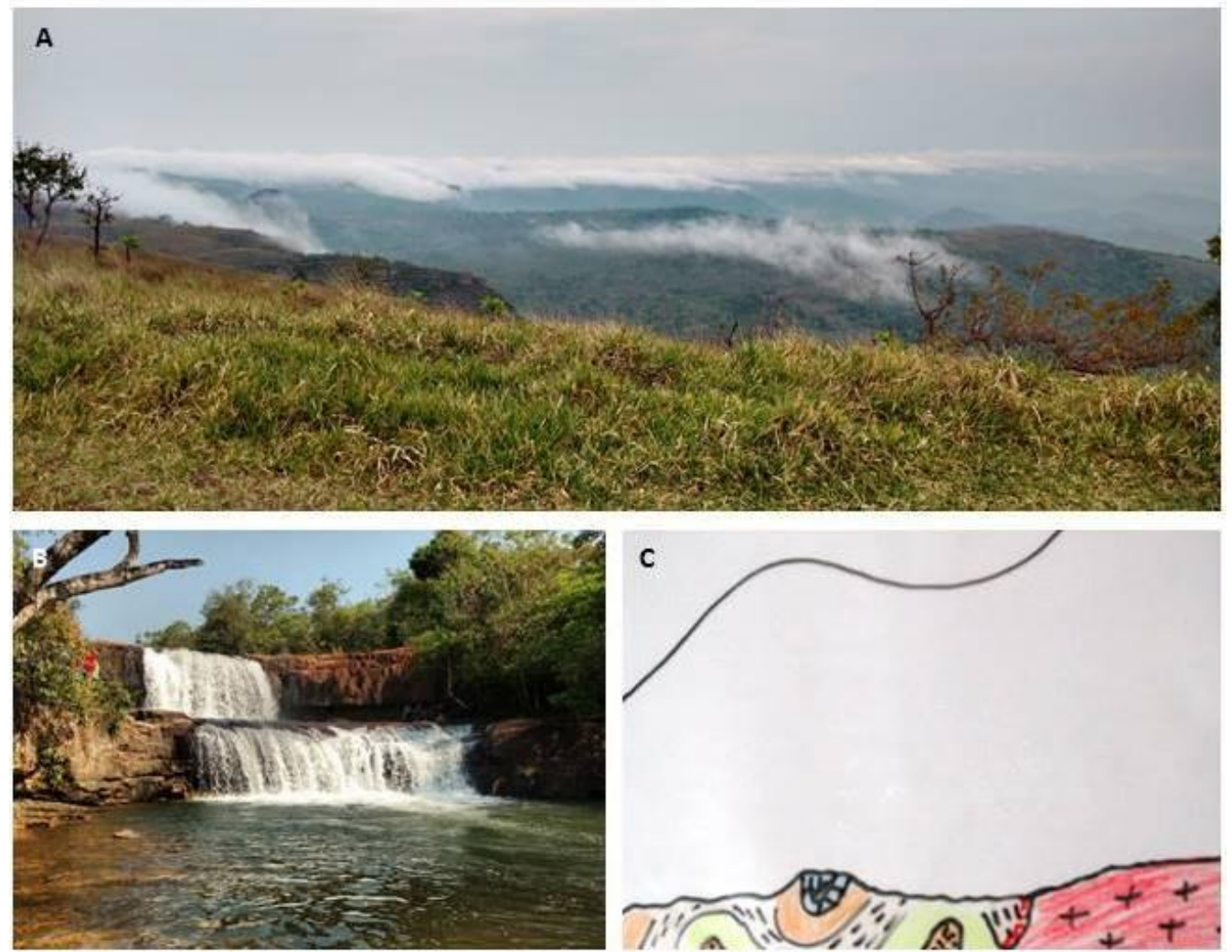

Figura 5: A) Vista esquerda observada no mirante do centro geodésico. B) Cachoeira da Martinha. C) Desenho esquemático, visando facilitar a explicação referente à profundidade em que são formadas as rochas ígneas intrusivas, na figura, a linha superior representa a altura da orogenia quando o granito de São Vicente foi formado. A linha inferior representa o nível erosivo anterior a deposição do Grupo Rio Ívai no Período Ordoviciano. 
PONTO 11 - A Cachoeira da Martinha (Figura 5, B)onde afloram os arenitos do Grupo Rio Ivaí de idade ordoviciana-siluriana, rochas que se formaram em um ambiente litorâneo. Esta foi a primeira unidade depositada na região, posterior a erosão da cadeia de montanhas da Faixa Paraguai.

Além dos pontos apresentados, o roteiro pode ser estendido para os municípios de Campo Verde ou/e Santo Antônio, visando a observação do Granito de São Vicente (Figura 5, C). Podem ser visitados pontos próximos a estrada ou então, uma alternativa, é a visita ao Hotel Mato Grosso Águas Quentes, onde além de observar as rochas graníticas existem piscinas termais.

\section{DISCUSSÕES}

A Geodiversidade pode ser observada em diferentes escalas observando os aspectos da geologia (rochas, minerais, fósseis), geomorfologia (relevo, processos) e características do solo (GRAY, 2004; PEREIRA et al 2013). Estes diferentes aspectos do meio físico normalmente não são abordados de forma integrada no processo educacional. $O$ desenvolvimento de roteiros didáticos facilita a realização de aulas de campo, visto que em alguns casos encontrar um afloramento com potencial educativo é uma dificuldade. Para Brilha (2009, p. 29):

[...] o simples fato de serem identificados geossítios de valor educativo já é uma relevante contribuição para o ensino da Geologia, facilitando assim a atividade dos professores que se sentem, frequentemente, inseguros no que diz respeito a efetuar aulas de campo.

Os elementos da geodiversidade que possuem uma grande importância científica ou estética, além de serem fundamentais no processo de aprendizagem, são também um patrimônio da humanidade e por isso precisam ser preservados. Estes elementos foram formados ao longo de toda a história do nosso planeta e são considerados recursos não renováveis, visto que uma vez destruídos não podem mais ser recuperados.

Sendo assim, o acesso aos geossítios é fundamental para a realização das aulas de campo de diversos cursos do ensino técnico e superior, visto que nestes locais o professor pode utilizar do patrimônio geológico para explicar os processos que regem nosso planeta. A degradação dos geossítios podem ter impactos 
negativos no processo de formação de toda uma comunidade. Conforme Brilha, (2009, p. 29),"a escassez de geossítios para uso educativo, situados a uma distância adequada dos respectivos estabelecimentos de ensino, condiciona o ensino das Geociências, em especial numa época de escassez de recursos financeiros."

Não é possível preservar o patrimônio geológico de uma determinada região sem que a população local também considere essa preservação como algo importante. Neste ponto é preciso ressaltar que no Brasil e em outros países o ensino em geociências é quase inexistente no processo educacional préuniversitário. O desenvolvimento deste roteiro pode auxiliar os professores das escolas locais. Para Brilha (2009) ao longo de décadas, as deficiências educacionais referentes a educação em geociências tem ocasionado que o cidadão médio tenha uma baixa percepção dos principais fundamentos das ciências geológicas e do seu real impacto na sociedade.

O roteiro desenvolvido pode ser utilizado como base por guias de turismo para esclarecer visitantes sobre os processos que deram origem a geologia, o relevo e solos, que circundam ou formam os atrativos turísticos. O desenvolvimento de material de apoio em linguagem adequada para os diferentes públicos é essencial para que as informações relativas ageodiversidade sejam assimiladas pelos visitantes, sejam eles acadêmicos de diferentes séries, ou turistas.

\section{CONSIDERAÇÕES FINAIS}

O roteiro apresentado integra atrativos turísticos com a geodiversidade local e pode ser utilizado para diferentes públicos e objetivos, desde um simples esclarecimento de uma dúvida de um turista, até a aplicação de uma aula interdiciplinar. Os afloramentos visitados permitem uma viagem no tempo, visitando rochas formadas em orogenias similiar ao Himalaia, passando por mares, desertos, rios e vulções. Além disso, o roteiro auxilia na comprensão dos processos intempéricos e pedogenéticos. Integrando estas informações é possível uma visão completa sobre a evolução da paisagem. 


\section{REFERÊNCIAS}

ALMEIDA, F.F.M. \& MANTOVANI, M.S.M. Geologia e geocronologia do Granito São Vicente, Mato Grosso. Anais da Academia Brasileira de Ciências, v. 47, p. 45158, 1975.

AMARAL, G.; CORDANI, U.G.; KAWASHITA, K.; REYNOLDS, J.H. Potassium-argon dates ofbasaltsfromsouthernBrazil. Geochimica et Cosmochimica Acta, v. 30, n. 2, p. 159-189, 1966.

ASSINE M. L., PERINOTTO J. A J., FÚLFARO V. J., PETRI S.. Progradação deltaica Tibagi no Devoniano Médio da Bacia do Paraná. Revista Brasileira de Geociências, 28(2): p. 125-134, 1998.

BOCARDI, L. B., ROSTIROLLA, S. P., DEGUCHI, M. G. F., MANCINI, F. História de soterramento e diagênese em arenitos do Grupo Itararé - implicações na qualidade de reservatórios; Revista Brasileira de Geociências 38(1:Suplemento), p. 207-216, março de 2008.

BRILHA, J. B. R; A. Importância dos Geoparques no Ensino e Divulgação das Geociências; Revista do Instituto de Geociências - USP; Publ. espec., São Paulo, v. 5, p. $27-33,2009$.

CAMARGO, L. (Org.). Atlas de Mato Grosso: abordagem socioeconômicoecológica. Entrelinhas.Cuiabá-MT, 96p. 2011.

CARVALHO, M. G. P., PONCIANO, L. C. M. O. The Devonian trilobites of Brazil: A summary; Journal of South American Earth Sciences, 64, p. 217-228. 2015.

CHIARAMONTI, P. C., GOMES, C. B., MIN, A., RUBERTI, E., GIRARDI, V. A.V., SLEJKO, F., NEDER, R. D., PINHO, F. E.C. Petrology of potassic alkaline ultramafic and carbonatitic rocks from Planalto da Serra (Mato Grosso State), Brazil. Central EuropeanJournalofGeosciences 6(4): 565-587. 2014.

COIMBRA, A.M. Bacias continentais cretáceas do centro-sul da Plataforma SulAmericana. Sistematização da obra. São Paulo, 1991. 54 p. Tese (Livre Docência) - Instituto de Geociências, Universidade de São Paulo.

DE MIN. A., HENDRIKS. B., SLEJKO F., COMIN-CHIARAMONTI P., GIRARDI. V., RUBERTI. E., GOMES. C. B., NEDER R. D. PINHO F. C., Age of ultramafic high-k rocks from Planalto da Serra (Mato Grosso, Brazil), Journal of South American Earth Sciences, 41, p. 57-64, 2013. 
DERBY, A. O. Nota sobre a geologia e paleontologia de Mato-Grosso. Arquivos do Museu Nacional. 9, 59-88 p, 1890.

FERNANDES, K. G.; KUHN, C. E. S.; SILVA, D. G. Q. R. Ensaio de uma correlação entre a caracterização petrográfica e lineamentos da Formação Paredão Grande nas regiões de Chapada dos Guimarães, Dom Aquino e Poxoréu - MT In: Anais do 48을 Congresso Brasileiro de Geologia, Porto Alegre, 2016.

FRANCO-ROSA, A.C., SALGADO, L., ROSAS, C.F., CARVALHO, I.S.

Nuevosmateriales de titanosaurios (sauropoda) enelCretacico Superior of Mato Grosso, Brasil. Rev. Bras. Paleontol. 7 (3), p. 329-336, 2004.

GIBSON, S. A., THOMPSON, R. N., WESKA, R. K., DICKIN, A. P., \& LEONARDOS, $\mathrm{O}$. H. Late Cretaceous rift-related upwelling and melting of the Trindade starting mantle plume head beneath western Brazil. Contributions to Mineralogy and Petrology,126(3), p. 303-314, 1997.

GRAY, M. Geodiversity: valuing and conserving abiotic nature.John Wiley \& Sons. 2004.

HASUI, Y. \& ALMEIDA, F.F.M. DE.Geocronologia do Centro-Oeste brasileiro. Boletim da Sociedade Brasileira de Geologia, v. 19, p. 1-26, 1970.

KUHN, C. E. S. Fácies sedimentares e estratigrafia da Bacia do Cambambe, Chapada dos Guimarães, Mato Grosso, Brasil. Dissertação (Mestrado) - Instituto de Ciências Exatas e da Terra, Universidade Federal de Mato Grosso. 109 p. 2014.

MACHADO, F. B., NARDY, A. J. R., ROCHA JÚNIOR, E. R. V., MARQUES, L. S., OLIVEIRA, M. A. F. Geologia e litogeoquímica da Formação Serra Geral nos estados de Mato Grosso e Mato Grosso do Sul. São Paulo, UNESP, Geociências, v. 28, n. 4, p. 523-540, 2009.

MANZANO, J. C., GODOY, A. M., ARAÚJO; L. M. B. Contexto tectônico dos granitóidesneoproterozóicos da faixa de dobramentos Paraguai, MS e MT. São Paulo, UNESP, Geociências, v. 27, n. 4, p. 493-507, 2008. 
Tese de Doutoramento, Universidade Federal do Rio Grande do Sul, Porto Alegre, 255 p. 1997.

PEREIRA, D. I., PEREIRA, P., BRILHA, J., SANTOS, L. Geodiversityassessmentof Paraná State (Brazil): aninnovative approach.Environmental Management,52(3), 541-552.2013.

PEREIRA, D; BRILHA, J; PEREIRA, P; Geodiversidade, valores e usos. Universidade do Minho, 16 p. 2008.

PIRES, E. F., GUERRA-SOMMER, M., DOS SANTOS SCHERER, C. M., DOS SANTOS, A. R., CARDOSO, E. EarlyCretaceousconiferouswoodsfrom a paleoerg (Paraná Basin, Brazil). Journalof South American Earth Sciences,32(1), 96-109. 2011.

PRADO, R. J., CABRAL, I. D. L. L., SILVA, A. P. M., SOLORZANO, P. E. M., \& DE ALBUQUERQUE, A. P. A. Caracterização de material laterítico do Planalto e Chapada dos Guimarães-MT por EDX, XRD e Espectroscopia Mössbauer. Revista Brasileira de Geomorfologia,15(4). 2014.

QUADROS, R.. Braquiópodes Devonianos do afloramento Topo de Fita Chapada dos Guimarães - Mato Grosso - Brasil. Dissertação de Mestrado,Instituto de Geociências, Universidade Federal do Rio Grande do Sul, 55p. 1979.

QUADROS, R. Paleontologia dos Brachiopoda - Lingulida, Strophomenida, Spiriferina, Terebratulida - devonianos, da Serra de Atimã e arredores, Mato Grosso, Brasil. Tese de Doutorado, Instituto de Geociências, Universidade Federal do Rio Grande do Sul, 87p. 1987.

SCHNEIDER, R. L.; MÜHLMANN, H.; TOMMASI, E.; MEDEIROS, R. A.; DAEMON, R. F.; NOGUEIRA, A. A. Revisão estratigráfica da Bacia do Paraná. XXVIII Congresso Brasileiro de Geologia, v. 1, p. 41-65. Porto Alegre: SBG. 1974.

SCHREINER, S. Clima e altitude em cidades tropicais: o exemplo de Chapada dos Guimarães e uma comparação com Cuiabá-MT. Dissertação, Mestrado em Geografia, UFMT. Cuiabá-MT, 2009. 116p.

SILVA, D. G. Q. R. A Sedimentação Neocretácea e a Influência Tectônica na Bacia de Poxoréo, Mato Grosso. Dissertação de Mestrado, Instituto de Ciências Exatas e da Terra, Universidade Federal de Mato Grosso. 54 p. 2014. 
SOUZA, A. B. S.; KUHN, C. E. S.; HIROOKA, S. H. Sauropodes e Teropode da Chapada dos Guimarães, Mato Grosso, Brasil. Congresso Brasileiro De

Paleontologia, Natal, Rio Grande do Norte, 22p, 2011.

TOKASHIKI, C. C., SAES, G. S. Revisão estratigráfica e faciologia do Grupo Cuiabá no alinhamento Cangas-Poconé, baixada Cuiabana, Mato Grosso. Revista Brasileira de Geociências, 38(4), 661-675. 2008.

VIEIRA JUNIOR, H. T; MORAES, J. M; SCHOBBENHAUS. C; Geoparque Chapada dos Guimarães-MT: proposta; SERVIÇO GEOLÓGICO DO BRASIL - CPRM, Goiânia, 2011.

WESKA, R.K. "Placers" diamantíferos da região de Água Fria, Chapada dos Guimarães, MT. Dissertação, Mestrado em Geologia Econômica e Prospecção, Departamento de Geociências, Universidade de Brasília.Brasília, 170 p.1987.

WESKA, R.K. Geologia da região diamantífera de Poxoréu e áreas adjacentes, Mato Grosso. São Paulo, 1996. 219 p. Tese (Doutorado) - Instituto de Geociências, Universidade de São Paulo.

WESKA, R.K.; SVISERO, D.P.; LEONARDOS, H.O. Contribuição ao conhecimento do Grupo Bauru no Estado de Mato Grosso, Brasil. In: Simpósio sobre o Cretáceo do Brasil, 4, 1996, São Pedro (SP). Boletim de Resumos. Rio Claro: UNESP, 1996, p. 289-295.

WESKA; R.K. Uma síntese do Cretáceo Superior Mato-Grossense. Geociências, v. 25, n. 1, p. 71-81, 2006.

ZOLINGER, I. T., SVISERO, D. P., WESKA, R. K. Morfologia cristalina de diamantes provenientes das regiões de Chapada dos Guimarães, Poxoréu, Paranatinga, Diamantino e Alto Paraguai - Mato Grosso. Revista do Instituto Geológico, São Paulo, 23(2), 23-33, 2002. 